\title{
EL DERECHO ANTE LA TÉCNICA DE EDICIÓN GENÉTICA. CRISPR
}

\author{
Ronald Cárdenas Krenz ${ }^{1}$
}

Resumen: La técnica de edición genética CRISPR constituye uno de los avances recientes más extraordinarios en materia de biotecnología, de alcances insospechados. En ese contexto, resulta fundamental analizar sus repercusiones en el ámbito de los derechos humanos, toda vez que, así como puede propiciar avances extraordinarios para su mejor desarrollo, puede también generar nuevas amenazas.

Palabras clave: CRISPR, bioderecho, biotecnología, edición genética

\section{The Law in front of the gene editing technique. CRISPR}

Abstract: The CRISPR genetic editing technique is one of the most extraordinary recent advances in biotechnology, whose scope is unsuspected. In this context, it is fundamental to analyze its repercussions in the field of the Human Rights, since as well as it can promote extraordinary advances for its better development, it can also generate new threats.

Keywords: CRISPR, biolaw, biotechnology, genetic edition

\section{O Direito ante a técnica da ediçáo genética. CRISPR}

Resumo: A técnica de edição genética CRISPR constitui um dos avanços recentes mais extraordinários em matéria de biotecnologia, de alcances insuspeitos. Neste contexto, é fundamental analisar suas repercussões no âmbito dos direitos humanos, toda vez que, assim como pode propiciar avanços extraordinários para seu melhor desenvolvimento, pode também gerar novas ameaças.

Palavras chave: CRISPR, biodireito, biotecnologia, edição genética

\footnotetext{
${ }^{1}$ Instituto de Investigación Científica (IDIC) y Facultad de Derecho de la Universidad de Lima. Academia de Derecho y Ciencias Sociales de Córdoba. Pontificia Academia para la Vida, Perú

Correspondencia: rcardena@ulima.edu.pe
} 


\section{Introducción}

La tecnología no solo permite conocer el mundo, sino transformarlo. No es ni buena ni mala, todo depende de lo que hagamos con ella, con todo lo que significa como posibilidad y como riesgo.

Una revolución tecnológica acaba de llegar a nosotros: la técnica de edición genética CRISPRCas9. Si bien el término habría surgido en 2001, en un intercambio virtual de comunicaciones entre el español Francisco Juan Martínez Mojica (Universidad de Alicante) y el holandés Rudd Jansen (Universidad de Utrecht), recién empieza a difundirse en 2012, como señala Kukso(1:60), cuando Jennifer Doudna, de la Universidad de California en Berkeley, junto con la francesa Emmanuelle Charpentier, del Centro Helmholtz de Investigación en Enfermedades Infecciosas, publicaron un artículo sobre el tema en la revista Science.

Dicha revista, en 2015, llamó a CRISPR el hallazgo científico del año; la revista Time, en junio de 2016, le dedicó una portada calificándola como "one of the most expansive frontiers ever contemplated by science”. También National Geographic le dedicó su carátula en diciembre del 2016, bajo el epígrafe "La revolución del ADN".

Algo similar han hecho Wired (agosto 2015), $\mathrm{Na}$ ture (marzo 2016), Tec Review (sept.-oct. 2016) o Investigación y Ciencia (octubre 2017).

En agosto de 2017, el más distinguido premio en medicina —el Albany Medical Center Prize in Medicine and Biomedical Research - fue concedido a cinco científicos vinculados con el desarrollo de la técnica: Charpentier, Doudna, Marraffini, Mojica y Zhang.

Ahora bien, como dicen Lamprea y Lizarazo-Cortés(2:104): "Si bien las tecnologías de edición de genes en general y, en particular CRISPR/Cas9, surgen en el ámbito de las biociencias, presentan numerosos retos para el derecho", agregando que "si bien es un tema técnico-científico, tiene numerosas implicaciones jurídicas, prácticas y bioéticas".

En 2017 Doudna y Sternberg afirmaban que la pregunta no era si la edición genética debería ser usada para alterar el ADN de células germinales humanas, sino más bien cuándo y cómo se dará. Hoy, ya sabemos ambas cosas. De hecho, la noticia difundida a fines del 2018, del nacimiento de dos niñas en China - Lulu y Nana_, tratadas genéticamente mediante esta técnica por $\mathrm{He}$ Jiankui, ha abierto la Caja de Pandora; ambas fueron editadas genéticamente para que, al nacer, no porten el virus del VIH que posee su padre. Aunque el trabajo no ha aparecido en ninguna revista científica, China ha prohibido a He continuar sus pruebas de edición genética, por haber violado la legislación china y considerarlas deplorables. No obstante los cuestionamientos a nivel internacional, ya otros científicos han anunciado que seguirán mismo pasos, como el biólogo ruso Denis Rebrikov, que ha solicitado permiso a su gobierno para intervenir embriones humanos.

Así, la técnica ha empezando a trasladarse del laboratorio a la clínica, con lo que el debate ya no es más hipotético.

El impacto de la técnica no se restringe al ámbito biológico o médico, pues se proyecta a lo social y hasta a nuestra propia comprensión del ser humano y del sentido de la tecnología; ante ello, el Derecho, que suele ir detrás de la ciencia, tiene ahora que apurar el paso.

\section{Metodología}

Para la elaboración del presente artículo, hemos partido de la revisión de bibliografía científica actualizada sobre la materia, analizándola a la luz de la doctrina, jurisprudencia y normas sobre derechos fundamentales. Se ha revisado, sobre todo, la información sobre la materia recopilada por el Grupo sobre Edición Genética de la Pontificia Academia para la Vida, integrado por investigadores de distintas partes del mundo; así como las bases de datos: Dialnet, DICE, DOAJ, EBSCO, EUR-Lex, IOP Science, Open Access Theses and Dissertations, Redalyc, Science Direct, entre otras fuentes.

\section{¿Qué es CRISPR?}

Siguiendo a Lamprea y Lizarazo-Cortés(2:79), es una especie de editor de textos, que permite cortar 
y pegar genes del genoma con una sencillez jamás vista y de modo barato, posibilitando identificar y eliminar el ADN defectuoso, y modificarlo o reemplazarlo con otro segmento. No solo puede corregir nuestro $\mathrm{ADN}$, sino también introducir alguna característica nueva, la cual se transmitirá a nuestros descendientes.

Como explica Bellver Capella(3:224), se trata de una región o secuencia del $\mathrm{ADN}$ que poseen algunas bacterias, que funciona como un mecanismo inmunitario ante los virus invasores. Cuenta con dos elementos básicos: el Cas 9, enzima que actúa como un "escalpelo genético" o "tijeras moleculares”, y CRISPR, que es una molécula de ARN, de las que suelen actuar como transmisoras de la información biológica en el genoma, que actúa como una especie de guía del "escalpelo" para dirigirse a una sección específica del $\operatorname{ADN}(3: 225,4)$.

La patente de la invención es disputada en Estados Unidos por la Universidad de California y el Broad Institute, de las universidades de Harvard y MIT, representada la primera por Jennifer Doudna y el segundo por Feng Zhang y George Church, en un conflicto legal aun inconcluso $(2,5,6)$.

Sus mayores avances están en China(7:29) y Estados Unidos(8), siendo también materia de importantes estudios en Suecia e Inglaterra.

En agosto de 2017, la revista Nature difundió la primera noticia conocida de una edición genética exitosa, sin mutaciones genéticas involuntarias, realizada por científicos de Portland (Oregon, EE.UU.), bajo la dirección de Shoukhrat Milatipov. Como explica Connor (2017), estos estudios pudieron superar algunos problemas técnicos ("mosaicismo"), advertidos previamente en China, que generaron escepticismo sobre la aplicación de la técnica en humanos. Las investigaciones norteamericanas permitieron corregir mutaciones genéticas en el $\mathrm{ADN}$ vinculadas con diversas enfermedades hereditarias, a través de la aplicación de CRISPR en las primeras etapas de la fertilización, corrigiendo genes defectuosos, causantes de enfermedades hereditarias, de modo seguro y eficiente, con cambios que pueden reflejarse en la línea germinal, pasando a otras generaciones.

Para tales resultados, fueron creados decenas de embriones humanos con fines experimentales; los embriones genéticamente modificados fueron destruidos dos días después de la fertilización (nunca hubo intención de implantarlos) ${ }^{2}$.

Las noticias de CRISPR no se detienen; en agosto del 2017 se logró por vez primera suprimir de nuestro genoma el gen de una grave enfermedad cardiaca; y, en febrero del 2018, se dio cuenta de que una poderosa enzima, modificada en el laboratorio, podría aumentar la utilidad de dicha técnica, haciéndola más versátil, al permitir realizar ajustes en más sitios del genoma y reducir la posibilidad de cambios no deseados(9). Por otro lado, en octubre del 2018 se dio a conocer que científicos en Estados Unidos y Suiza utilizaron la técnica en ratones para su edición genética, a fin de prevenir desórdenes metabólicos mortales, conforme estudios publicados en la revista Nature.

Adicionalmente, en marzo de 2019, la Organización Mundial de la Salud (OMS) ha afirmado que sería una "irresponsabilidad" científica realizar estudios de edición de genes humanos en personas, proponiendo un registro central de investigaciones en aras de la transparencia.

Sobre el estado actual del avance de la técnica, puede decirse sintéticamente lo siguiente:

"Today, biologists have learned to reprogram CRISPR-Cas9 to cut any type of DNA in a cell - not just viral — in a location of their choosing by giving it a new target to seek out. They've also discovered that after the DNA is cut by Cas9, cells will try to repair the break in the DNA. That repair system can then be manipulated into using a template provided by scientists, effectively cutting out one gene and replaicing it with another" (8:31).

\section{Importancia de la técnica}

Estamos ante el hito más importante en la historia

\footnotetext{
2 "Beyond the 'success' achieved by the application of the technique, it should be remembered that dozens of human beings, created specifically by means of artificial insemination so that CRISPR may be applied at the embryonic stage, become experimental objects and are then eliminated". Pontifical Academy for Life. Disponible en: http:// www.academiavita.org/_articles/621758128-genetic_editing_and_ human_life.php
} 
de la genética desde el descubrimiento del ADN; una herramienta extraordinaria de edición, "cuyas aplicaciones no parecen tener límites”(10:22), salvo nuestra imaginación. El procedimiento permite modificar el ADN a voluntad, y reescribir el código genético.

Sus alcances, además, podrían transformar el debate sobre los transgénicos y la manipulación genética en general(11:1-8), obligando a revisar la definición de qué es un organismo modificado genéticamente.

La novedad de la técnica es su bajo costo y accesibilidad, con las ventajas y riesgos que ello implica, en una democratización de la tecnología sin precedentes.

\section{Promesas y posibilidades}

1. Modificación fácil y rápida del ADN de cualquier ser vivo.

2. Tratamiento y/o eliminación de enfermedades al corregir mutaciones genéticas; detener la reproducción de células cancerígenas o hacer que las células sean impermeables al SIDA. Vale decir que, en noviembre de 2016, en Sichuan (China), se pudo alterar un gen humano para tratar un cáncer, usando CRISPR-Cas 9. También se piensa que podría servir contra las enfermedades de Tay-Sachs, anemia falciforme y beta-talasemia, entre otras. Además, podría aplicarse para enfrentar la distrofia muscular de Duchenne(12:169) y curar enfermedades cardíacas(13).

3. Prevención de enfermedades y corrección de fallas genéticas en embriones, incluyendo la distrofia muscular, fibrosis quística, hepatitis, Huntington, diabetes tipo I y esclerosis lateral amiotrófica(14).

4. Acentuar un rasgo genético o generar nuevas formas de inmunidad que se transmitirán a la descendencia. En agosto del 2017, Nature ${ }^{3}$ dio cuenta que científicos norteamericanos, usando CRISPR-Cas9, habían logrado corregir una mutación que originaba una enfermedad cardíaca, librando al resto de generaciones.

${ }_{3}^{3}$ Disponible en https://www.nature.com/nature/journal/vaop/ncurrent/full/nature23305.html.
5. Ajustar los medicamentos al perfil genético del paciente.

6. Cura contra el dengue, zika, malaria y otras enfermedades, a través de la edición de genes.

7. Retrasar el envejecimiento(15:180).

8. Facilitar los xenotrasplantes para humanos, al poder eliminar los virus de los porcinos (la especie más parecida a nosotros $)^{4}$.

9. Mejorar la producción mundial de alimentos haciéndolos más nutritivos, y reforzar la seguridad alimentaria $(16)^{5}$; aumentar la velocidad de las cosechas, hacer que las vacas produzcan más leche, y contar con un medio menos perjudicial de mejora vegetal $(6: 10-16)^{6}$.

10. Aumentar el tiempo de vida y la resistencia de frutos como el tomate, para facilitar su exportación (se ha hecho ya en Japón). Existen también hoy los champiñones CRISPR, creados genéticamente para que no se pongan de color pardo.

11. Proteger mejor a los cultivos frente a plagas, enfermedades, problemas climáticos, plantas invasoras $(11: 3)^{7}$ y la contaminación radiacti$\mathrm{va}^{8}(17: 10)$.

12. Reducir la dependencia de plaguicidas tóxicos.

13. Nuevas fuentes de energía limpia, como la producción biológica del etanol(18:57-59) u otros biocombustibles.

\footnotetext{
${ }^{4}$ Agosto del 2017: la revista Science dio cuenta que, a través de CRISPR-Cas9, se había logrado inactivar los genes de virus latentes en embriones de cerdos que impedían su uso para trasplantes.

5 "With the ability to guide plants down different paths of cultivation, or to explore what would happen if our ancestors had picked different crops. CRISPR has turned speculation into reality -just in time for a future that will have more mouths to feed than ever before".

${ }^{6}$ En China se ha creado el salmón del Atlántico AquAdvantage, que puede lograr el tamaño necesario para ser comercializado en tiempo dos veces más rápido que el salmón ordinario, además de consumir menos alimentos y criarse más cerca de las ciudades, reduciendo costos.

${ }^{7}$ En 2014, científicos chinos la utilizaron para crear trigo panificable resistente a la antigua plaga del oídio.

${ }^{8}$ Como da cuenta Investigación y Ciencia, ya se viene aplicando para inactivar, en el arroz, el transporte del cesio radiactivo del suelo, liberado de los accidentes en la central nuclear de Fukushina, en 2011.
} 
14. Producir cabras (y otros animales) más resistentes a enfermedades y naranjas dulces enriquecidas con vitaminas.

15. "Revivir" especies extintas o preservarlas. Así, en el 2015, George Church, profesor de la Universidad de Harvard, y su equipo, anunciaron que trabajarían en la creación de un elefante-mamut, utilizando CRISPR-Cas9.

\section{Riesgos e inquietudes}

1. Manipulación de embriones y creación de "bebés de diseño". En abril de 2015, generando un gran debate, se informó que científicos habían usado la técnica CRISPR para la ingeniería de embriones humanos, aun cuando no llegó a resultar en un nacimiento.

2. Posibilidad de ediciones riesgosas del genoma, generando consecuencias graves para la salud, incluyendo mutaciones inesperadas? Advierten Mojica y Almendros(10:27) que un inconveniente de la inmunidad que posibilita CRISPR es la posibilidad de "actuar sobre el genoma residente, con consecuencias que van desde la generación de mutaciones hasta la muerte celular". Un estudio publicado en julio de 2018, en Nature Biotechnolo$g y(19)$, ha puesto en evidencia la posibilidad de alteraciones no queridas del ADN, lo cual puede complicar los esfuerzos de diseñar terapias basadas en CRISP; dado que los mecanismos de uso de la técnica no siempre trabajan perfectamente, puede generarse que segmentos del ADN sean borrados, reacomodados o incorporados en el cromosoma(20).

3. Descontrol de la técnica, pudiendo generar fatales efectos, al crearse organismos genéticamente modificados, nuevas clases de insectos o perturbación de ecosistemas. Esta inseguridad puede determinar la alteración de genes que no eran el objetivo de la intervención (off-target) o la producción de efectos secundarios no deseados, pese a cumplir con el fin de la intervención, causando graves daños (on-target) a los pacientes o a sus descendien-

\footnotetext{
${ }^{9}$ A mediados de 2017, un estudio desarrollado en ratones por investigadores del Columbia University Medical Center, sugirió que la técnica de edición genética CRISPR puede generar cientos de inesperadas mutaciones en el genoma humano.
}

tes $(15: 180)$.

4. Generación de efectos negativos extensivos a futuras generaciones.

5. Posibilidad de cambios genéticos en una población, aun en contra de su voluntad.

6. Errores o dificultades vinculados con la aplicación de la técnica que, por ejemplo, lleven al crecimiento de las células, derivando en problemas de cáncer. En junio de 2018 la revista Nature Medicine dio a conocer dos artículos - uno de un equipo de la farmacéutica Novartis en Boston y otro de investigadores del Instituto Karolinska de Suecia- conforme a los cuales la aplicación de CRISPR podría facilitar la aparición de tumores. En otros casos, los problemas tienen que ver con la defensa inmunitaria de los pacientes.

7. Uso perverso de la técnica, creándose nuevas armas biológicas. Es de mencionar que los organismos de inteligencia norteamericanos han incluido a CRISPR entre las armas de destrucción masiva(1:64).

8. Riesgos en la preservación de ecosistemas, incluyendo los efectos de eliminar especies aparentemente sin importancia, pero con impredecibles consecuencias, al afectar la cadena alimenticia y el equilibrio ambiental.

9. Limitaciones de la técnica en sí (es mejor que anteriores, pero no infalible).

10. Derivar en nuevas formas de eugenesia.

11. Dotar a los animales de discutibles capacidades.

12. Uso frívolo de la técnica. Comenta Hall(11:2) que artistas y bioempresarios la han usado para crear conejos color púrpura o animales vivos como souvenirs, tal como ha ocurrido en China con la creación de cerdos miniaturizados como mascotas.

13. Generación de nuevas formas de desigualdad y discriminación; creación de quimeras o híbridos; generación de efectos no queridos en otros genes. 
En cuanto a la aplicación de la técnica para crear el primer "bebé CRISPR", no se conoce nada todavía, aunque es cuestión de tiempo que pueda darse, no obstante la discusión jurídica y moral.

Se plantea que si CRISPR puede facilitar "crear" perros más musculosos con fines militares o policiales, ¿cuánto faltará para que pretenda hacerse lo mismo con humanos?

\section{Algunas respuestas del Derecho}

Las posiciones legales sobre la materia vienen oscilando entre una luz roja a los avances, una luz verde, o una luz amarilla planteando su aplicación con precaución(21:1). ${ }^{10}$ Todo parece indicar que será imposible detener su aplicación, por lo que los esfuerzos deberían orientarse entonces a encauzar las investigaciones para evitar desbordes.

Respecto a la aplicación de la técnica, la Unión Europea, en la Directiva 98/44/CE del Parlamento Europeo y del Consejo (1998), relativa a la protección jurídica de las invenciones biotecnológicas, prohíbe las patentes de los procedimientos de modificación de la identidad genética germinal del ser humano (artículo $6^{\circ}$, inciso 1, apartado b.).

Vale decir, la patentabilidad de modificaciones en la línea germinal está prohibida en diversos países como Albania, Alemania, Dinamarca, Eslovaquia, España, Finlandia, Hungría, Noruega, Portugal y Serbia, Suecia y Suiza; en el derecho colombiano y andino tampoco serían actualmente patentables los procedimientos para modificar y las modificaciones a líneas germinales humanas(2:93).

Empero, el tema no es solo una cuestión jurídica sobre patentes, pues involucra también al derecho civil, al derecho penal y, por cierto, a los derechos humanos, toda vez que la integridad, la libertad, la dignidad, la salud y la vida misma pueden verse afectados con la técnica.

\section{Una cuestión esencial: la edición genética de seres humanos}

El más delicado y polémico aspecto de la aplica-

\footnotetext{
10 "(I) proffer the following mandate: proceed with caution. Don't stop. Keep driving ahead, constantly assessing the harm-benefit risk. Watch about for pot holes and avoid swerving into a ditch" (21:2).
}

ción de la técnica de edición genética CRISPR se relaciona con las posibilidades que ofrece para editar la línea germinal humana, corrigiendo un defecto genético, acentuando determinados rasgos o creándolos, y pasando dicho cambio a las siguientes generaciones.

El primer anuncio de la edición genética de embriones humanos fue hecho por científicos de Portland (Oregon, Estados Unidos), del cual diera cuenta la revista Nature en agosto de 2017. Su importancia se relaciona con que la eficiencia, precisión y seguridad de la aplicación de la técnica ofrecen un gran potencial para la corrección dirigida de mutaciones hereditarias en la línea germinal en seres humanos, complementando el diagnóstico genético; sin embargo: "much remains to be considered before clinical applications, including the reproducibility of the technique with other heterozygous mutations" (22:413).

Respecto a la edición de seres humanos, el 14 de febrero de 2017, en Estados Unidos, la Academia de Ciencias y la Academia de Medicina publicaron el informe Human Gene Editing: Science, Ethics and Governance, preparado por el Comité sobre la Edición de Genes Humanos: Consideraciones Científicas, Médicas y Éticas, conformado por representantes de diversos países, incluyendo universidades, institutos de investigación, ONGs y empresas.

El informe ha sido analizado rigurosamente por Gamboa-Bernal(23) en un valioso estudio, destacando, entre otras ideas, lo siguiente:

1. Advertencia de preocupación en la opinión pública sobre el uso de la técnica para modificar rasgos o habilidades básicas: inteligencia, fuerza física, destrezas, etc.

2. Se reconoce que, al menos, es polémica la posibilidad de propiciar cambios genéticos que vayan a ser heredados, siendo un avance que se piense en las próximas generaciones.

3. Se afirma categóricamente que esta aplicación no está lista para probarse en humanos, pero es solo cuestión de tiempo que ello suceda. 
4. Se recomienda promover el bien-estar, siendo que parece que debería importar más el bienser.

5. El principio de transparencia no parece suficientemente considerado.

6. Apelar a los altos estándares de investigación, solo tomando como referencia normas internacionales, es insuficiente.

El informe habla de respeto a las personas, pero no proscribe la eugenesia, y más bien la respalda encubiertamente. La edición genética, en la línea germinal, se contempla como una posibilidad futura, tal vez cuando la opinión pública sea más favorable, respondiendo a estrategias de aceptabilidad y de mercadeo(23:8-9).

Se habla de distribuir equilibradamente no solo los beneficios, sino también los riesgos, al amparo de una supuesta justicia distributiva, siendo que los riesgos no forman parte del bien común, como anota el citado autor.

El esbozo de argumentos para realizar la edición de la línea germinal del genoma humano a futuro, se contradice con el acuerdo internacional de prohibirla.

Sobre esto último, la Directiva 98/44/CE del Parlamento Europeo y del Consejo de 6 de julio de 1998, sobre protección jurídica de las invenciones biotecnológicas, se refiere, en su parte considerativa, a la necesidad del respeto al orden público y la moralidad en el terreno, debido al considerable alcance de las consecuencias potenciales de la invención. Agrega que "en el seno de la Unión Europea existe consenso respecto de que la intervención génica germinal en seres humanos y la clonación de seres humanos son contrarios al orden público y a la moralidad", agregando que es necesario, por lo tanto, excluir explícitamente de la patentabilidad los procedimientos de modificación de la identidad genética germinal humana y los procedimientos de clonación de seres humanos".

Para una revisión más completa de la regulación jurídica de la edición genética en la línea germinal humana, puede verse el excelente trabajo de Be- llver Capella(3), quien explica que, mientras en Estados Unidos "existe un marco legal escaso y se deja a la autorregulación de los científicos la ordenación de la edición genética, en Europa se encuentra con una base normativa clara, como es el Convenio de Oviedo, que debe ser respetada por los Estados que lo ratificaron e inspirar las regulaciones más específicas que se aprueben” (3:232).

A ello se agrega, internacionalmente, lo dispuesto en la Declaración Universal sobre el Genoma y los Derechos Humanos de la UNESCO (1997), cuyo artículo 24 in fine se refiere a la necesidad de estar atentos "a la identificación de prácticas que pueden ir en contra de la dignidad humana, como las intervenciones en la línea germinal”.

Sintetizando las respuestas que han dado los Estados a la edición genética en embriones humanos, Bellver(3:233) resume el estado de las cosas como sigue:

1. Países que no regulan nada sobre la materia (lo más común en donde apenas hay investigación sobre el particular).

2. Países con regulación restrictiva (Estados Unidos).

3. Países con marco regulatorio ambiguo (Argentina).

4. Países que la prohíben a través de directrices no coactivas (China).

5. Países que la prohíben a través de leyes sancionadoras (Alemania y Reino Unido; este último prohíbe la edición genética clínica pero no la orientada a la investigación).

Sin perjuicio de ello es necesario advertir, con el mismo autor, que aunque aparentemente existe una resistencia política, jurídica y científica a las intervenciones genéticas en la línea germinal humana, pareciera ser una posición transitoria: "Ni los científicos ni los Estados, ni las organizaciones internacionales pretenden construir cortafuegos que impidan la creación de seres humanos genéticamente modificados en el futuro. Más bien han establecido 'controles de aduana' para que, en la medida de lo posible, el territorio de la investigación sea transitado por grupos responsables, en el 
sentido de que no pongan en riesgo la confianza del público en esas investigaciones. No se piensa en la protección al embrión humano, ni en los riesgos de acabar legitimando por igual la edición genética destinada a fines clínicos que a fines de mejora: lo único que parece preocupar es que se produzca un escándalo que eche por tierra un área de desarrollo tecnológico y comercial con mucho futuro"(3:234).

Jennifer Doudna y Sternberg plantean también sus reservas respecto a la aplicación de la técnica para modificar la línea germinal humana: "I've come to see a clear boundary between the procedures described in this chapter and those involves in germline editing. We should think twice before crossing that line. And then we should think again"(12:183).

\section{Discusión}

La tecnología es esencial para el desarrollo y el bienestar del ser humano; sin embargo, los conocimientos limitados, el mal uso y los riesgos propios que puede generar, demandan un necesario y adecuado control, tarea en la que juega un papel fundamental el Derecho, más allá de las simples declaraciones.

Luego del asombro que pueden generar los nuevos descubrimientos, es imprescindible medir cuidadosamente sus alcances, ponderando si los beneficios potenciales compensan los riesgos que puedan generar, tarea que debe plantearse desde una perspectiva bioética.

En ese sentido, es urgente promover la reflexión en torno a avances como la técnica de edición genética CRISPR, ya que, sin perjuicio de sus buenos usos, puede también generar peligrosos riesgos que pueden trascender irreversiblemente a la sociedad y a nuestra propia condición humana.

Dicho análisis debe hacerse desde una perspectiva bioética y biojurídica, considerando que, en diversos casos, no estamos ante meros dilemas éticos individuales, sino más bien socialmente trascendentes, lo cual es un aspecto que explica la "novedad" de la bioética, como bien anota Aga$\operatorname{zzi}(24: 8)$.
Es esencial definir, entonces, determinados límites éticos, los que deben estar aparejados, en su caso, también de límites jurídicos.

Como ya se dijo, no se trata tan solo de buscar el bien-estar, sino más todavía, el bien-ser, siendo de considerar en el logro de estos propósitos otros principios fundamentales, como respeto a la dignidad de las personas, transparencia, responsabilidad, equidad, solidaridad, cooperación, preocupación y pro-debilis, desde una perspectiva de los derechos humanos.

Así, pareciera pertinente establecer la posibilidad de la aplicación de la técnica CRISPR si se usa en células, mas no en embriones, como señala Domenico Coviello(25). También, sobre la base del principio del consentimiento informado, puede usarse para curar enfermedades, aliviar sus efectos o con fines de diagnóstico, pero no para producir seres humanos modificados genéticamente.

Otro límite es que no puede justificarse la intervención en la línea germinal humana en nombre de la autonomía de los padres, pues no estamos ante derechos individuales de los progenitores, sino de sus hijos, quienes no pueden someterse a la arbitrariedad de aquéllos.

Las modificaciones en la línea germinal afectan no solo a una persona individualmente, sino que, de una u otra manera, pueden terminar repercutiendo en la humanidad. Siendo que no hay suficiente consenso, es oportuno apelar a una moratoria hasta contar con estudios más completos que permitan reducir al mínimo consecuencias indeseadas.

Nos encontramos en un conflicto entre dos ideas: We can do it, then we should do it, y, por otro lado, la de: Can does not mandate "ought", particularmente en el área de la genética(21:1).

Esta técnica, sencilla, barata, eficaz y multifuncional, debe ir acompañada en su desarrollo de la reflexión ética, social, científica y ecológica, teniendo en cuenta que se trata de una tecnología aún insegura.

El llamado a la cautela en su aplicación no es solo por las dudas técnicas que ofrece, sino también 
- y esencialmente- por las dudas morales y jurídicas que genera, y la necesidad de proteger al embrión como vida humana, el cual no puede reducirse a un simple objeto de investigación ni a mera biología.

Debe dejarse de lado cualquier perspectiva que cosifique $(3: 237)^{11}$ al ser humano, respetando tanto su dignidad como su identidad.

La experimentación con embriones solo puede permitirse en beneficio de éste y no de terceros.

El uso de la técnica en embriones congelados que no van a ser transferidos, parece una posibilidad inaceptable y discriminadora; el embrión congelado, vaya a ser implantado o no, es un ser humano.

Modificar el genoma de nuestros descendientes en la medida que brinde beneficios relevantes, es una cuestión que debe analizarse con mucho cuidado, por lo subjetivo que puede tener, los posibles riesgos colaterales, la relatividad del criterio de lo que es "relevante" y la necesidad de velar por la integridad del ser humano.

Cualquier regulación que se haga sobre la materia, debe revisarse periódicamente, a fin de poder actualizarla a la luz de los avances científicos.

En el contexto del desarrollo de la tecnociencia, con insólitos poderes ahora a nuestro alcance, lo trascendental ya no son solo los conocimientos a los que podemos acceder, sino las nuevas capacidades de cambiar la naturaleza, especialmente la humana, en sus niveles más profundos.

$\mathrm{Al}$ margen de una inflación de expectativas, debe advertirse, al menos por ahora, que las bondades de la técnica CRISPR todavía no están del todo comprobadas. Así, por ejemplo, un estudio publicado en mayo del 2017 en la revista Nature Methods(26) dio cuenta de la existencia de un número alarmante de las llamadas "mutaciones fuera de destino" en ratones sometidos a una terapia experimental de reparación de genes, para corregir una mutación genética vinculada con una forma de ceguera, con lo que podríamos estar ante una deficiencia potencialmente fatal, como se ha advertido. Naturalmente, queda por aclarar si el

\footnotetext{
11 “... la posibilidad de que unas personas decidan las características genéticas de otras no pueden verse sino como la máxima expresión de arrogancia, paternalismo y cosificación de la vida humana”.
}

problema se debió a la técnica en sí o a una falla en el experimento realizado.

Sea como sea, como reconocen Doudna y Sternberg(12:160), existen desafíos éticos y de seguridad que deben enfrentarse ${ }^{12}$.

En concordancia con Specter(7:12), "Ningún descubrimiento del último siglo ha sido tan prometedor ni planteado cuestionamientos éticos más perturbadores".

Estamos ante una revolución genómica que nos conduciría al paso del homo sapiens al homo geneticus-geneticus, lo que lleva a preguntarse si todo lo que la ciencia y la técnica hacen posible debe realizarse, sin tener en cuenta su viabilidad ética, moral y social.

En tal virtud, es importante contar con normas y criterios claros para determinar dicha responsabilidad, lo que demanda también un debido conocimiento de la materia por parte de los encargados de juzgar dichos actos. Como dice Sherkow(6:29): "It seems, then, that the development of CRISPR as a technology is a study as much of law as science". La tecnología está yendo mucho más rápido que la reflexión jurídica, no pudiendo predecirse las consecuencias.

En todo caso, parece claro que cualquier cambio debe hacerse preservando la posibilidad de dejarlo sin efecto, teniendo en cuenta las consecuencias que podrían producirse a futuro, más allá de cualquier buena intención. No vaya a ser que, cuando nos demos cuenta, no exista ya la posibilidad de dar marcha atrás.

Dada la facilidad y accesibilidad de la técnica, sería impráctica la prohibición total de la ingeniería genética en humanos; aparte, varios pedidos de moratoria no se han sustentado en razones morales, sino meramente técnicas; también se ha dicho que dicha prohibición generaría un mercado negro y un turismo médico no controlado o biotecnológico, de muy difícil persecusión(2:84-93,15:183).

Sea como sea, debe insistirse en que, como lo hicieron público un grupo de científicos en una

\footnotetext{
${ }^{12}$ But while germline editing has been useful as a research tool in lab mice, its use in humans poses significant safety and ethical challenges".
} 
carta publicada en Nature en marzo del 2015: "la edición del genoma en embriones humanos utilizando las tecnologías actuales podría tener efectos impredecibles sobre las generaciones futuras. Esto lo hace peligroso y éticamente inaceptable. Tal investigación podría ser empleada para producir modificaciones no terapéuticas", entre otras consideraciones ${ }^{13}$.

La actitud "fronética" es esencial. Empero, habría que ver qué tan presente está Aristóteles en nuestro pensamiento cuando, por ejemplo, las noticias nos reportan avances en el advenimiento de quimeras. En febrero del 2018 una noticia daba cuenta de la creación de embriones de ovejas, en las que una de cada 10.000 de sus células era de naturaleza humana, estudio realizado por investigadores de las universidades de Californa y de Stanford.

El estudio se relaciona con la necesidad de atender la alta demanda de órganos para transplante, planteándose entonces la posibilidad de los xenotrasplantes, mediante el cultivo de órganos en animales para su posterior implantación en humanos, utilizándose células del destinatario para evitar el rechazo. En China ya se modifican córneas de cerdo para trasplantarlas a humanos(7:15).

Ya un año antes, el español Juan Carlos Izpisua Belmonte y su equipo del Salk Institute for Biological Studies de California, presentaron la primera de estas "quimeras": embriones de cerdos a los que se había inyectado células madres de un humano, siendo implantados en el útero de cerdas. Se crearon 150 embriones, siendo de naturaleza humana una de cada una de sus 100.000 células; la gestación fue interrumpida por razones éticas 28 días después, una vez confirmada la aplicabilidad de la técnica.

Para Hiro Nakauchi, de la Universidad de Stanford, en 5 a 10 años pueden empezar a darse este

\footnotetext{
13 "In our view, genome editing in human embryos using current technologies could have unpredictable effects on future generations. This makes it dangerous and ethically unacceptable. Such research could be exploited for non-therapeutic modifications. We are concerned that a public outcry about such an ethical breach could hinder a promising area of therapeutic development, namely making genetic changes that cannot be inherited.

At this early stage, scientists should agree not to modify the DNA of human reproductive cells (...)" (Lanphier et al, 2015, p. 410).
}

tipo de trasplantes en humanos. La pregunta es si estaremos jurídicamente preparados para ello, como ante todas las nuevas posibilidades que ofrece o no debería ofrecer CRISP-Cas9.

\section{Conclusiones}

El Derecho no puede ser ajeno a las nuevas posibilidades vinculadas con la edición genética a partir de la técnica CRISP-Cas 9. Urge una respuesta jurídica ante los nuevos debates que se plantean, más allá de las declaraciones éticas o de principio.

Si bien existen algunas normas sobre el tema, especialmente en Europa, ellas no son suficientes, debiendo tenerse en cuenta que no se trata de simples cuestiones industriales sino de temas que involucran derechos humanos, temas vinculados con la vida, la salud, la dignidad, la integridad y la identidad de las personas.

La atención primordial en la materia se realciona con la necesidad de establecer la prohibición de las modificaciones en la línea germinal, como ya existe en algunos países; o, en todo caso, por lo menos una moratoria en su aplicación, para un debate más amplio y estudios más completos respecto de los riesgos de la técnica.

La tecnología debe orientarse tanto al bien-estar como al bien-ser del ser humano, y el Derecho debe velar por ello, desde una mirada en la que se combinen lo bioético con lo biojurídico, teniendo siempre presente el consentimiento informado, y que no todo lo técnicamente posible es jurídicamente aceptable.

\section{Agradecimientos}

El presente artículo ha sido realizado con el auspicio del Instituto de Investigación Científica de la Universidad de Lima, contando con la valiosa colaboración, como asistente de investigación, del estudiante Edwin Francisco Córdova Pérez, de la Facultad de Derecho de dicha universidad.

Conflictos de interés: El autor declara no tener ningún conflicto de interés. 


\section{Referencias}

1. Kukso, F. ¿Podemos corregir a la naturaleza? Tec Review 2016 Octubre; 58-65.

2. Lamprea Bermudez, N, Lizarazo-Cortés, Ó. Técnica de edición de genes CRISP/CAS9. Retos jurídicos para su regulación y uso en Colombia. La Propiedad Inmaterial 2016; 21: 79-110.

3. Bellver Capella, V. La revolución de la edición genética mediante CRISPR-Cas9 y los desafíos éticos y regulatorios que comporta. Cuadernos de Bioética 2016; XXVII(2): 223-239.

4. Park, A. A new technique that lets scientists edit DNA is transforming Science and raising difficult questions. Time 2016, 23 de junio.

5. Sherkow, J. S. Who owns gene editing? Patents in the time of CRISPR. Biochemical Society 2016: 26-29.

6. Sherkow, J. S. Inventive steps: the CRISPR patent dispute and scientific progress. EMBO Reports 2017; 18(7): 10471051.

7. Specter, M. La revolución del ADN. National Geographic, agosto 2016.

8. Groves, A. Repairing the Future. Discover 209; 40(4): 29-31.

9. $\mathrm{Hu}, \mathrm{JH}$, Miller SM, Geurts, MH, et al. Evolved Cas9 variants with broad PAM compatibility and high DNA specificity. Nature 2018; 556: 57-63. DOI: http://dx.doi.org/10.1038/nature26155 (2018).

10. Mojica JM, Almendros C. Descubrimiento del sistema CRISPR- Cas. Investigación y Ciencia 2017: 21-28.

11. Hall SS. CRISPR llega a los cultivos. Investigación y Ciencia 2016; 480.

12. Doudna JA, Sternberg SH. A Crack in Creation. Gene editing and the unthinkable power to control evolution. Boston: Houghton Mifflin Harcourt; 2017.

13. King A. A CRISPR edit for heart disease. Nature 2018, March 7. Available from: https://www.nature.com/articles/ d41586-018-02482-4

14. Wang L, Yi F, Fu L, et al. CRISPR/Cas9-mediated targeted gene correction in amyotrophic lateral sclerosis patient iPSCs. Protein Cell 2017; 8(5): 365-378. DOI: 10.1007/s13238-017-0397-3.

15. De Miguel Beriain I, Armaza Armaza E. Un análisis ético de las nuevas tecnologías de edición genética: el CRISPR-Cas9 a debate. Anales de la Cátedra Francisco Suárez 2018; 52: 179-200.

16. Keats J. Domestication 2.0. Discover 2019; 40(4): 10-11.

17. Nieves-Cordones M. La técnica CRISPR permite obtener cultivos resistentes a la contaminación radiactiva. Investigación y Ciencia 2017: 10-12.

18. Maxmen A. The Genesis Engine. Wired 2015; 23.

19. Kosicki M, Tomberg K, Bradley A. (2018). Repair of double-strand breaks induced by CRISPR-Cas9 leads to large deletions and complex rearrangements. Nature Biotechnology 2018; 36: 765. DOI: dx.doi.org/10.1038/nbt.4192

20. Ledford H. CRISPR gene editing produces unwanted DNA deletions. Nature 2018. Disponible en: https://www. nature.com/articles/d41586-018-05736-3. 23/07/2018

21. Peters T. Should CRISPR Scientists Play Good. Religions 2017; 8: 61. Available from: www.mpdi.com/journal/religions.

22. Hong M, Marti-Gutierrez N, et al. Corrections of a pathogenic gene mutation in human embryos. Nature 2017; 548: 413-436. DOI: 10.1038/nature23305.

23. Gamboa-Bernal GA. Un empeño científico a gran escala: La eugenesia. Persona y Bioética 2017; 21(1): 6-13.

24. Agazzi E. Bioethics as a paradigm of an ethics for a technological society. Bioethics Update 2015; 1(1): 5-21.

25. Negrotti E. C'e una barriera da rispettare (Entrevista a Domenico Coviello). Primo Piano, 2018.

26. Schaefer, Kellie A, Wu WH, Colgan DF, et al. Unexpected mutations after CRISPR-Cas9 editing in vivo. Nature Methods 2017; 14: 547-548. Available from: https:/www.nature.com/nmeth/journal/v14/n6/full/nmeth.4293.html

Recibido: 17 de junio de 2018

Aceptado: 19 de julio de 2019 